\title{
The Emotional Status among Evacuees from Fukushima Nuclear Accident (2): Evaluation of Tentative Theories
}

\author{
Ayako Hashizume ${ }^{1}$ \\ I'Faculty of System Design, Tokyo Metropolitan University, Japan)
}

\begin{abstract}
Since the Great East Japan Earthquake in 2011, more than five years have passed. However, seriously affected areas have not been revived yet. People in the disaster area have been living as evacuees for a long time, with the anxiety that people's attention is fading and the restless urge that reconstruction is not smooth. In the surveys by the local government, evacuees have complained about the lack of information in their lives. In this paper, the author is focusing on the issue of the lack of information that affects the evacuees, and examines its regulation factor.
\end{abstract}

Keywords - Fukushima nuclear accident, inadequate supply of information, information shortage, evacuated townspeople, questionnaire survey

\section{INTRODUCTION}

More than five years have passed since the Great East Japan Earthquake in 2011. The disaster's worst affects were the severe earthquake, tsunami and Fukushima nuclear accident, and the affected areas have not been revived yet. The Namie town, Fukushima prefecture is located near the Tokyo Electric Power Company's Fukushima nuclear power plant. The townspeople of Namie sought refuge in areas throughout Japan, due to the Fukushima nuclear power plant accident. The areas affected by the radioactive contamination from the at the Fukushima nuclear accident are confronted with a difficult situation as to whether the local communities themselves can survive to begin with, aside from the issue of restoring them.

In order to correspond to the opinion of information shortage from town people, the Namie town office is performing information distribution to town people under refuge to every place positively using various means, including public relations magazines, internet websites, and data distribution by digital photo frame, and so on. However, according to questionnaire surveys conducted every year by the public office, the percentage of the people who feel "shortage of information about daily life" has reached 20 percent [1-2]. There is fear that the dearth of information will lead to the aversion of the town, and it may interfere with the revival of the town [3-4]. It is necessary to clarify the regulation factor of a feeling of information shortage, and to consider the relief policy.

This study focuses on the issue of the sense of inadequate supply of information felt by the evacuated townspeople of Namie, Fukushima prefecture, and will examine its regulation factor. The aim is to contribute toward improving and resolving issues surrounding Namie and other disaster struck municipalities. To grasp the level of frustration on "inadequate supply of information regarding living conditions" held by the evacuated townspeople of Namie, has analyzed the results of previous surveys by the public office of Namie town. Then author conducted surveys by qualitative and quantitative approaches concerning the receiving of information on living conditions to these evacuated townspeople.

In the preceding paper, the previously analyzed surveys results [1-2] by the public office of Namie town, and the conducted interview surveys results, have derived the following 9 theories on the receiving information by them [5-6].

(a). There is no shortage of information on supply upon people's daily living situation.

(b). There is a lack of information needed to help people construct their future life plan.

(c). The stronger the people's "desire to return back to their hometown", the more active they are in gathering information and therefore, their satisfaction level regarding information is higher

(d). Evacuees within the prefecture tend to have a higher level of satisfaction with information than evacuees outside of the prefecture (evacuees outside of the prefecture have a low level of interest).

(e). The level of satisfaction with information is different depending on the living arrangement (temporary housing, public housing, rented house, owned house)

(f). The level of satisfaction with information is higher for younger people due to their IT savviness (younger they are, the higher the satisfaction)

(g). People who participate in town exchange events do not feel much shortage of information since they are able to obtain information face-to-face. 
(h). Since the information provided by the local governing body only comes in the form of results, there is a sense of a lack of information regarding the process behind arriving at such a result.

(i). The desire for returning back to their hometowns is decreasing.

And then, a questionnaire survey was conducted targeting the entire townspeople to verify the derived theories and to grasp quantitative information. This paper is reporting the evaluation of the above tentative theories derived from qualitative surveys results.

\section{METHOD}

We conducted a questionnaire survey through mail by targeting evacuees of Namie, Fukushima who are evacuated throughout Japan (46 prefectures with exclusion of Wakayama prefecture, as of September 30, 2012). Out of entire 9,869 households of Namie, we targeted 4,253 evacuee households. The survey was conducted between July 1 and July 20, 2013.

In addition to demographic information such as gender, age etc., we asked 22 questions such as desire for returning back to hometown, information environment, information activity, distressed or inconvenienced circumstances regarding their living conditions at evacuation site, their current state of mind, etc.

\section{RESULTS}

The response rate of the survey was $43.1 \%$. Based on the gathered result of the survey, we performed the following verification of above theories (a) to (i) derived in the preceding paper [5].

\subsection{Theories (a), (b)}

In regard to theory (a) and (b), we asked them whether there is a shortage of information concerning their current living conditions at the evacuation site. By listing 12 categories of information, these items corresponded to our theory, due to the reason that feelings of inadequacy among people were low. Information concerning everyday living conditions at evacuation sites such as information on shopping and medical institutions as shown in Figure 1 were not enough. On the other hand, the result showed a large sense of inadequacy for information pertaining future life plans such as compensation and reconstruction plan, state of Namie town and townspeople.

\section{$3.2 \quad$ Theory (c)}

In regard to theory (c), when we tallied the differences in "desire for returning back to hometown" (4 steps) and satisfaction level of information being provided from the public office of Namie town, the level of "desire for returning back to hometown" and the satisfaction level of "information being provided from the public office" were in proportion to each other and as predicted by our theory, the result showed that the higher the desire for returning back to hometown, the higher the satisfaction level of information.

\subsection{Theory (d)}

When we estimated cross tabulation according to the current evacuated sites (divided into 14 areas nationwide) and the satisfaction level of information being provided by the public office of Namie town, regarding the satisfaction level of information between evacuees within the prefecture and evacuees outside of the prefectures, the satisfaction level among evacuees outside of the prefecture scored slightly higher (response ratio of people who said they are satisfied: overall $=41.4 \%$, evacuees within prefecture $=40.4 \%$, evacuees outside of the prefecture $=44.4 \%$ ), thus scoring a result different to our theory. Further, for evacuees within the prefecture, the result showed that evacuees living in Nihonmatsu city (where temporary public office is located) scored the lowest ratio of satisfaction level (34.1\%), and evacuees from Iwaki city scored the highest (48.6\%).

\subsection{Theory (e)}

A cross-tabulation results according to the current arrangement of living (8 categories) and the satisfaction level of information provided by the public office of Namie town, showed the satisfaction level among public housing residents scoring higher level of satisfaction $(42.4 \%)$ over temporary housing residents $(35.8 \%)$. This result turned out differently from our theory since we theorized that the temporary housing residents' satisfaction level would score higher due to the availability of information. 


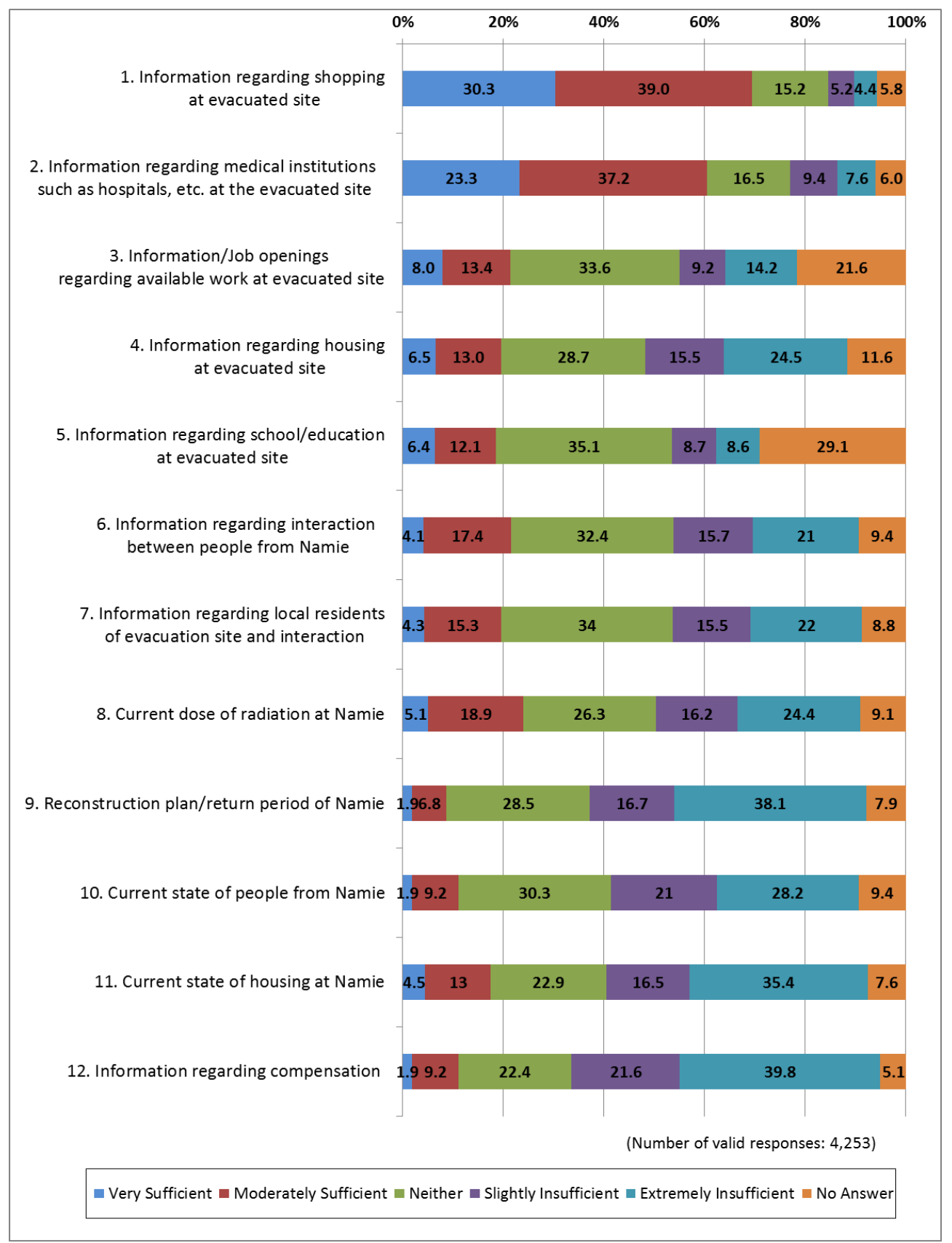

Figure 1. Sense of Inadequacy Regarding Information on Evacuation Life.

\subsection{Theory (f)}

When we tallied the satisfaction level of information being provided by the public office of Namie by categorizing them into different age groups ( 8 categories of 20-90's), the ratio of people who responded "satisfied" came out to be roughly $40 \%$ of the entire age group, and the ratio of people who responded "unsatisfied" came out to be $15.8 \%$ for people of 30 's and under, and $27.4 \%$ for people of 40 's and above, showing a high level of unsatisfied people among age groups over 40 . On the other hand, the ratio of people who responded "neither" was higher in younger age groups, showing a result slightly different from our theory.

\subsection{Theory $(g)$}

When we tallied the satisfaction level of participation state of townspeople exchange events (3 categories) and information being provided by the public office of Namie town, the ratio of people who responded "satisfied" scored $43.2 \%$, for those who have attended exchange events, and $40.8 \%$ for those who have not participated, thus showing a result with higher satisfaction level for people who participated in the exchange events as predicted by our theory. Out of the people who never participated in the townspeople exchange event, people who did not know about such an exchange event scored $32.2 \%$ on their satisfaction level 
regarding the information being provided by the public office of Namie city, showing a result with an especially low level of satisfaction.

\subsection{Theory (h)}

When we tallied the satisfaction level of information being provided by the public office of Namie town ( 2 categories of "satisfied", "unsatisfied") and shortage of information concerning the current evacuation living conditions (14 categories), in regard to the ratio of respondents who requested information regarding the "direction of mayor", $21.2 \%$ responded "satisfied" and $32.4 \%$ responded "unsatisfied" for the providing of information.

Furthermore, in regard to the ratio of respondents who requested information regarding the "state of assembly meetings", $21.4 \%$ responded "satisfied" and $29.8 \%$ responded "unsatisfied" with the information provided. In regards to the ratios of requests concerning information other than "direction of mayor" and "state of assembly meetings", we did not see any correlation with the satisfaction level and the information provided. Compared to the people who answered "satisfied" with the providing of information, there was a higher ratio of people who answered "unsatisfied" with requests for information regarding "direction of mayor" and "state of assembly meetings", which relates to the process of policy decisions concerning the future of the town, showing virtually identical results as predicted by our theory.

\subsection{Theory (i)}

In regards to the decrease of "desire to return to their hometown", when we compared the "desire to return to their hometown" from the previous survey by the public office of Namie on June 2012 and this survey, it showed that those who responded "I want to go back to Namie" dropped $(44.3 \%$ in the previous survey, $32.9 \%$ in this survey), and those who responded "unsure" increased (26.1\% in the previous survey, $35.6 \%$ in this survey), as predicted by our theory. Based on this result, it can be said that insecurity and sense of uncertainty toward their future increases as "desire for returning back to their hometown" decreases.

\section{DISCUSSION}

In the following, we will examine our (d), (e) and (f) theories that went against the tally results of the survey. First, we looked into theory (d) and (e). We tallied the result in which items are constructed into 6 cases (since temporary facilities are not available outside of the prefecture) by categorizing "desire for returning back to hometown" into "I want to return" and "I don't want to return", residential region into "within Fukushima prefecture" and "outside of Fukushima prefecture", living arrangement into "temporary housing" and "public housing", and the satisfaction level with the information being provided by the public office of Namie (Table 1). The finding showed that people with high level of "desire for returning back to hometown" scored high for their satisfaction level of information, regardless of their living region or living arrangement. On the other hand, people with low level of "desire to return to their hometown" who are also living in temporary housing within the prefecture scored especially low on their satisfaction level of information, alongside scoring high on their frustration level. Based on these facts, it became clear that people under this category were the ones who are the reason for the low rate of satisfaction level of evacuees within the prefecture and temporary housing.

Regarding the response for questions pertaining to per-age-group satisfaction level of information provided by the public office of Namie, the ratio of people responding with "neither" increased as the age became younger. When we tallied "current state of mindset" (displayed 13, multiple response included) based on age group, the ratio of people who responded with "I want to be a resident of Namie for the rest of my life" came out to be $31.2 \%$ for those under 30, a low percentage compared those over 40 that showed $46.2 \%$. On the other hand, the ratio was high for people who responded with "I have already rehabilitated my living conditions up to a certain degree" (under 30 's $=20.2 \%$, over 40 's $=10.8 \%$ ). In particular, compared to other age groups, a

Table 1. Satisfaction Level of Information Based on Combination of "Desire to Return to Hometown", Evacuated Region, and Living Arrangement.

\begin{tabular}{|c|c|c|c|c|c|}
\hline $\begin{array}{c}\text { "Desire to return to hometown", } \\
\text { evacuated region and living } \\
\text { arrangement }\end{array}$ & $\begin{array}{c}\text { (Number of } \\
\text { respondents) }\end{array}$ & $\begin{array}{c}\text { Satisfied } \\
(\%)\end{array}$ & $\begin{array}{c}\text { Neither } \\
(\%)\end{array}$ & $\begin{array}{c}\text { Unsatisfied } \\
(\%)\end{array}$ & $\begin{array}{c}\text { No } \\
\text { response } \\
(\%)\end{array}$ \\
\hline $\begin{array}{c}\text { No intention to return, } \\
\text { within the prefecture, temporary } \\
\text { housing }\end{array}$ & 233 & 26.2 & 32.6 & 39.9 & 1.3 \\
\hline $\begin{array}{c}\text { No intention to return, } \\
\text { within the prefecture, public }\end{array}$ & 508 & 40.1 & 30.3 & 28.8 & 0.8 \\
\hline
\end{tabular}




\begin{tabular}{|c|c|c|c|c|c|}
\hline housing & & & & & \\
\hline $\begin{array}{c}\text { No intention to return, } \\
\text { outside of the prefecture, public } \\
\text { housing }\end{array}$ & 176 & 38.7 & 31.3 & 30.0 & 0 \\
\hline $\begin{array}{c}\text { Desire to return, } \\
\text { within the prefecture, temporary } \\
\text { housing }\end{array}$ & 438 & 45.3 & 23.5 & 29.7 & 1.5 \\
\hline $\begin{array}{c}\text { Desire to return, } \\
\text { within the prefecture, public } \\
\text { housing }\end{array}$ & 514 & 47.1 & 29.4 & 22.9 & 0.6 \\
\hline $\begin{array}{c}\text { Desire to return, } \\
\text { outside of the prefecture, public } \\
\text { housing }\end{array}$ & 139 & 46.0 & 28.1 & 24.5 & 1.4 \\
\hline
\end{tabular}

low ratio of respondents under $20(26.7 \%)$ answered "I want to be a resident of Namie for the rest of my life", and a high ratio (24.4\%) answered "I have already rehabilitated my living conditions up to a certain degree". Based on these results, the reason for resulting in such a high ratio of "neither" regarding the satisfaction level of information being provided by the public office of Namie, can be attributed to the fact that young people are losing interest in Namie, with such tendency increasing the lower the age group of the respondents.

\section{CONCLUSION}

This study focused on the issue of the lack of information given to the evacuated townspeople of Namie, Fukushima prefecture, and will examine its regulation factor. It conducted surveys by qualitative and quantitative approaches concerning the information received on living conditions to these evacuated townspeople. In the preceding paper, it analyzed the questionnaires results by the public office of Namie town and the interview surveys results, then derived the theories on the information received by the evacuated townspeople. In this paper, it conducted the questionnaire survey for all the townspeople of Namie, and analyzed the results for evaluating the tentative theories.

The survey results revealed that the reason why people feel a sense of inadequacy regarding the information on the evacuation life is not due to a lack of actual information for their lives being provided by the public office, but such sentiment is rather stemming from the current state of having a difficult time maintaining the community of Namie as to how it was prior to the disaster, along with people's insecurity toward not being able to foresee their future life plan.

All in all, this report revealed that in order to reconstruct Namie town alongside resolving corresponding issues, there is a great need to implement thorough information, revitalize the bond between the townspeople of Namie, and promote coordinated cooperation toward reconstruction with people outside of Namie.

\section{REFERENCES}

[1] The Namie town, Fukushima prefecture, Results of of the First Townspeople Survey on Reconstruction, the Public Office of Namie Town, 2011.

[2] The Namie town, Fukushima prefecture, Results of of the Second Townspeople Survey on Reconstruction, the Public Office of Namie Town, 2012.

[3] A. Hashizume, Analysis of a Feeling Uninformed and the Determining Factors among Evacuees from Nuclear Accident on 3.11, JSKE Proceedings 2013, 2013.

[4] A. Hashizume, An Evaluation of the Uses and Applications of ICTs for Reconstructing Communities in Disaster-Affected Areas, Communications in Information Science and Management Engineering,.4(3), 2014, 29-33.

[5] R. Saito, A report on the Access to the Information for Everyday Life in Namie, Fukushima, Nextcom, 17, 2014, 38-51.

[6] A. Hashizume, The Emotional Status among Evacuees from Fukushima Nuclear Accident (1): Analysis of the Feelings of Information Shortage by Qualitative Approach, IOSR Journal of Humanities and Social Science, 21(8), 2016, 23-27. 